\title{
ERRATUM
}

\section{Measuring and quantifying dynamic visual signals in jumping spiders}

\author{
Damian O. Elias · Bruce R. Land • \\ Andrew C. Mason · Ronald R. Hoy
}

Published online: 5 May 2006

(C) Springer-Verlag 2006

\section{J Comp Physiol A (2006) DOI 10.1007/s00359-006-0116-7}

In the original publication, red color had been erroneously used for the lettering in Fig. 5.

Figure 5 is shown with correct lettering below.

The online version of the original article can be found at http:// dx.doi.org/10.1007/s00359-006-0116-7

D. O. Elias · B. R. Land · R. R. Hoy

Department of Neurobiology and Behavior,

Cornell University, Seeley G. Mudd Hall, Ithaca,

NY 14853, USA

D. O. Elias $(\bowtie) \cdot$ A. C. Mason

Department of Life Sciences,

Integrative Behaviour and Neuroscience,

University of Toronto at Scarborough,

1265 Military Trail, Scarborough,

ON M1C 1A4, Canada

e-mail: doe2@cornell.edu

B. R. Land

e-mail: brl4@cornell.edu 
i.

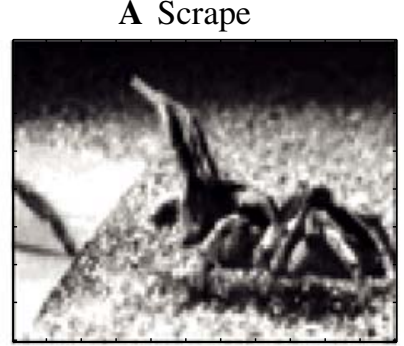

ii.

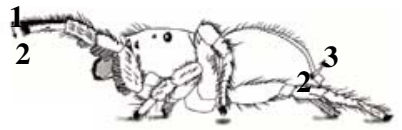

iii.

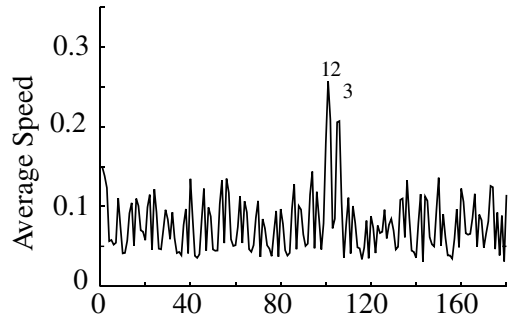

iv.

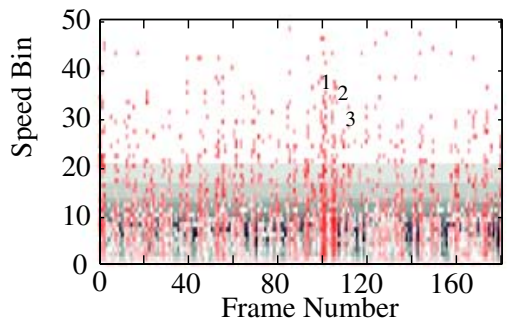

V.

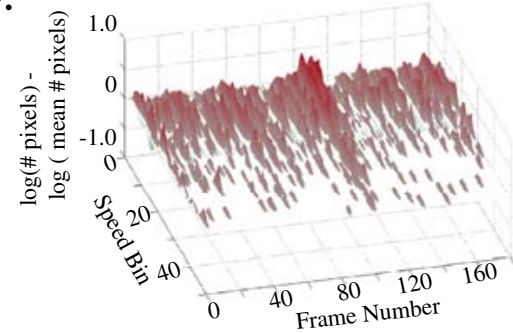

B Thump
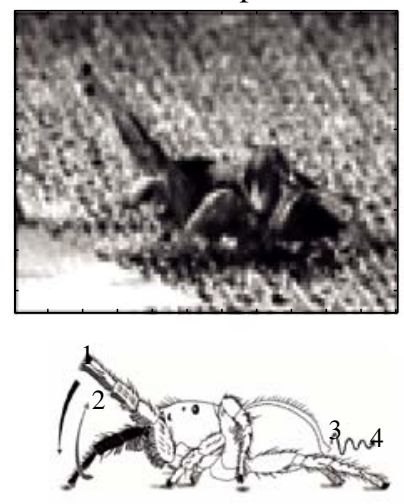

C Buzz
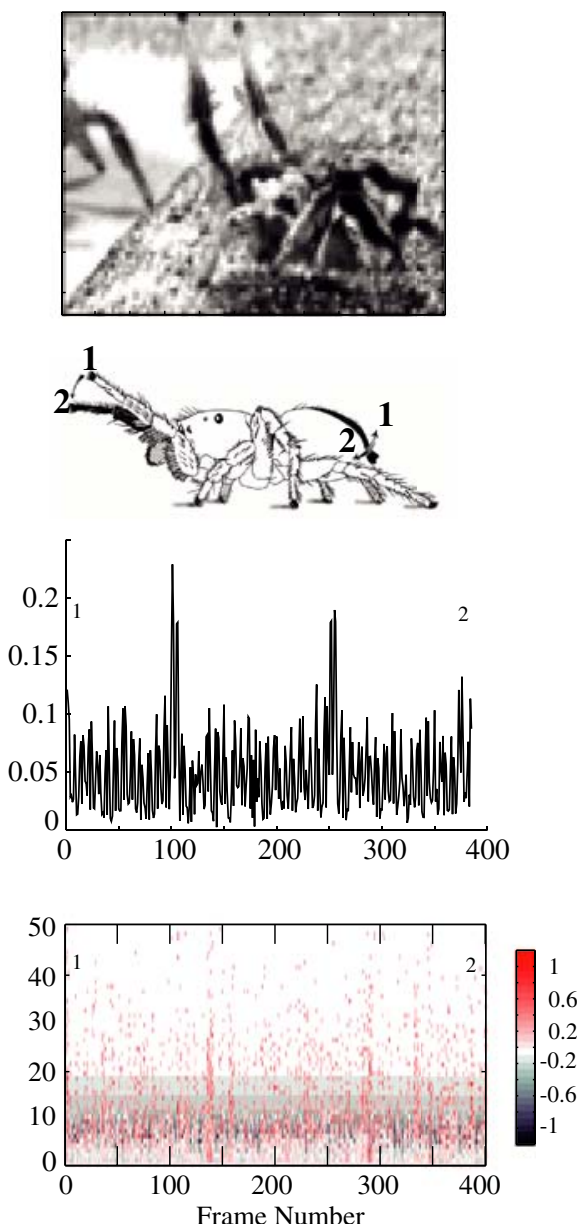

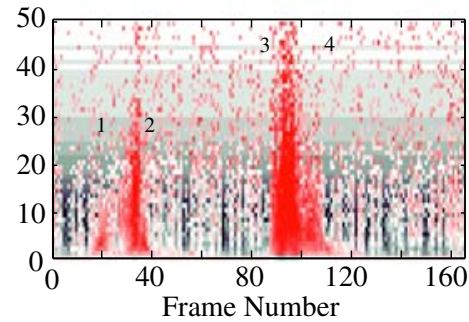

0
0.2
.2
-6
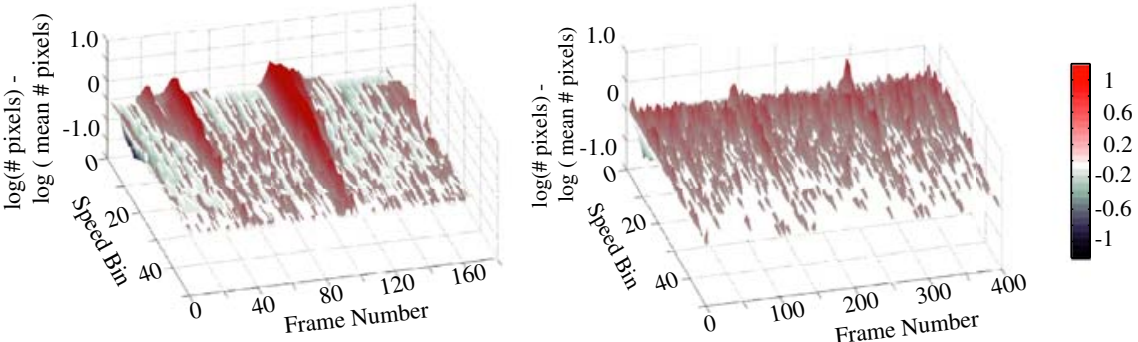

Fig. 5 Different signals of Habronattus dossenus. Representative examples of scrape (a), thump (b), and buzz (c) signals are shown. Top panel $(i)$ shows an example of a single video frame at the resolution used in the analysis. Second panel (ii) illustrates body positions with numbers (1-4) illustrating movements of the forelegs and abdomen. Third panel (iii) shows the 2D "speed waveform" plots. Fourth panel (iv) shows the 3D "speed surface" plots. Fifth panel (v) shows the 3D "speed waterfall plots". Panels $i i i-v$ are shown in the same time scale, with numbers (1-4) corresponding to the body movements illustrated in panel ii. Frame rate is $250 \mathrm{fps}$ (reduced from $500 \mathrm{fps}$ ) 